\title{
Antropología, etnicidad y las implicaciones del Multiculturalismo en la Sierra Nevada de Santa Marta
}

\author{
Anthropology, ethnicity and the implications of Multiculturalism \\ in the Sierra Nevada de Santa Marta \\ Antropologia, etnia e as implicações do Multiculturalismo \\ na Sierra Nevada de Santa Marta \\ Marisel Montero Carpio ${ }^{1}$ \\ Universidad Autónoma de San Luis Potosí, México.
}

Para citaciones: Montero, M. (2020).

Antropología, etnicidad y las implicaciones del Multiculturalismo en la Sierra Nevada de Santa Marta. El taller de la Historia, 12(2), $462-480$.

Recibido: Abril de 2020

Aprobado: Octubre de 2020

Autor de correspondencia:

Marisel Montero Carpio

maryiec08@gmail.com

Editor: Sergio Paolo Solano. Universidad de Cartagena-Colombia.

Tipología IBN Publindex:

Artículo de Investigación
Copyright: () 2020. Montero, M. Este es un artículo de acceso abierto, distribuido bajo los términos de la licencia https://creativecommons.org/licenses/bync-sa/4.0/ la cual permite el uso $\sin$ restricciones, distribución y reproducción en cualquier medio, siempre y cuando que el original, el autor y la fuente sean acreditados.

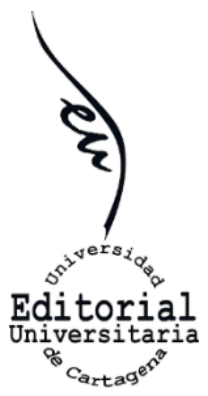

\section{RESUMEN}

Cuando hablamos de multiculturalismo, se nos viene la noción de una palabra que permite la incorporación inequívoca y absoluta del dialogo intercultural en una sociedad, este dialogo permite la comunicación continua entre diferentes actores sociales y culturas; que se complementan y se articulan desde todos sus autocriterios, practicas, visiones y relaciones sociales, económicas, culturales y jurídicas. No obstante, y como pretendemos demostrar en este trabajo, esa idea multiculturalista está lejos de ser cierta y exitosamente aplicable en nuestros actuales Estados nacionales. En el presente trabajo, abordaremos la implementación de la idea multiculturalista en la realidad constitucional de Colombia, para ello, espacialmente, trasladaremos dicho análisis a la experimentación multiculturalista que el Estado colombiano ha implementado en la sierra Nevada de Santa Marta. De igual forma, analizaremos, el papel de la antropología en el uso y puesta en marcha de ese experimento, es por ello, que las primeras hojas de este trabajo, se centraran en abordar algunas nociones básicas de los orígenes, características y funcionalidades de la antropología en Colombia, y específicamente en la Sierra Nevada de Santa Marta. Al final, concluiremos, planteando algunas inquietudes, y haciendo algunas anotaciones, sobre algunos errores que se cometen al no abordar de forma responsable, horizontal y dialógicamente la Antropología, teniendo en cuenta el importante papel que ha cumplido y cumple esta disciplina en las relaciones sociales y en las implementaciones de acciones y políticas públicas nacionales.

Palabras clave: Multiculturalismo; Antropología; pueblos originarios.

\begin{abstract}
When we speak of multiculturalism, the notion of a word that allows the unequivocal and absolute incorporation of intercultural dialogue in a society comes to mind, this dialogue allows continuous communication between different social actors and cultures; that complement and articulate themselves from all their self-criteria, practices, visions and social, economic, cultural and legal relations. However, and as we intend to demonstrate in this paper, this multiculturalist idea is far from being

\footnotetext{
${ }^{1}$ Historiadora. Maestría en Derechos Humanos de la Universidad Autónoma de San Luis Potosí (UASLP). Miembro del semillero de investigación Sociedad, Raza y poder del Instituto Internacional de Estudios del Caribe. Universidad de Cartagena.
} 
true and successfully applicable in our current nation states. In this paper, we will address the implementation of the multiculturalist idea in the constitutional reality of Colombia, for this purpose, spatially, we will transfer such analysis to the multiculturalist experimentation that the Colombian State has implemented in the Sierra Nevada de Santa Marta. Similarly, we will analyze the role of anthropology in the use and implementation of this experiment, which is why the first pages of this paper will focus on addressing some basic notions of the origins, characteristics and functionalities of anthropology in Colombia, and specifically in the Sierra Nevada de Santa Marta. At the end, we will conclude, raising some concerns, and making some annotations, about some mistakes that are made by not approaching Anthropology in a responsible, horizontal and dialogic way, taking into account the important role that this discipline has played and plays in social relations and in the implementation of actions and national public policies.

Keywords: Multiculturalism, Anthropology, Original Towns.

\section{RESUMEM}

Quando falamos de multiculturalismo, criamos a noção de palavra que permite a incorporação inequívoca e absoluta do diálogo intercultural em uma sociedade, esse diálogo permite a comunicação contínua entre diferentes atores e culturas sociais; que complementam e se articulam a partir de todos os seus auto-critérios, práticas, visões e relações sociais, econômicas, culturais e jurídicas. No entanto, como buscamos demonstrar neste trabalho, essa ideia multiculturalista está longe de ser verdadeira e com sucesso aplicável em nossos estados-nação atuais. Neste artigo, abordaremos a implementação da ideia multiculturalista na realidade constitucional da Colômbia, para isso, espacialmente, vamos transferir esta análise para a experimentação multiculturalista que o Estado colombiano implementou na Sierra Nevada de Santa Marta. Da mesma forma, vamos analisar, o papel da antropologia no uso e implementação desse experimento, é por isso que as primeiras folhas deste trabalho se concentraram em abordar algumas noções básicas das origens, características e funcionalidades da antropologia na Colômbia, e especificamente na Sierra Nevada de Santa Marta. No final, concluiremos, levantando algumas preocupações, e fazendo algumas anotações, sobre alguns erros que são cometidos ao não abordar a Antropologia de forma responsável, horizontal e dialogal, tendo em conta o importante papel que essa disciplina tem desempenhado e cumpre nas relações sociais e na implementação de ações nacionais e políticas públicas.

Palavras-chave: Multiculturalismo, Antropologia, povos nativos.

\section{Introducción}

Dentro de todas las ciencias sociales, se ha dado el interés por crear conceptos, darle nombre a las cosas, a la vida del ser humano, y si ya tenían un nombre, se empieza a trabajar en una nueva forma de renombrarlos. Esto fue justo lo que ocurrió con la Sierra Nevada de Santa Marta a finales del siglo XIX. Pero antes de entrar en materia, y explicar ¿cómo fue el proceso académico e institucional, mediante el cual la Sierra fue incorporada al proyecto de desarrollo económico del Estado colombiano?; nos centraremos en explicar 
los orígenes de la antropología en Colombia y la responsabilidad que esta tuvo en esa incorporación y definición de la Sierra; teniendo en cuenta, que hoy, casi todas las definiciones que explican la Sierra, la hacen trayendo a colación esos primeros estudios antropológicos.

Como bien sabemos, la antropología como disciplina independiente se crea a mediados del siglo XIX, tras las sombras de las ideas evolucionistas que se consolidaban en el momento. Es por ello, que sus inicios, especialmente en América, estuvieron marcados por la identificación, descripción y "comprensión" de los pueblos indígenas de cada uno de los países Americanos. Esta fue sin duda la gran característica o la carta de presentación de los antropólogos a lo largo de todo el siglo XX. No obstante, dicha ciencia se ha ido ampliando, y debido a la crítica que recibió por sus ideas evolucionistas, se tuvo que reinventar, no solo en la práctica, sino en la praxis y en sus campos de estudio. Hoy día, hablamos de una antropología social, una antropología jurídica, una antropología rural, urbana, ambiental, etcétera. Sin embargo, y para el objetivo del presente trabajo, nos remontaremos a analizar los inicios de esa antropología, y nos centraremos en esos inicios evolucionistas y funcionalistas de esta disciplina, porque son a través de ellos que se da en Colombia, la reinvención de la noción indígena, y la reconstrucción conceptual de la Sierra Nevada de Santa Marta. Para ello, partiremos de una idea general, sobe esos inicios antropológicos de clasificación y conceptualización territorial.

A mediados del siglo XIX los científicos de la sociedad y de la naturaleza interpretaban la historia y la realidad como una escalada de estadios que van de los más inferiores a los más avanzados. Algunos de los trabajos pioneros que representaron dicha interpretación, fueron los de Lewis Henry Morgan y Henri Maine; quienes a partir de su interpretación entre sociedad, derecho y costumbres, contribuyeron al surgimiento de la antropología jurídica. Dentro de estos dos estudios, analizamos con más detenimiento el esquema de evolución social de Morgan, para él la historia humana podía ser dividida en tres grandes "periodos étnicos". Salvajismo, barbarie y civilización. E1 salvajismo y la barbarie se subdividían en periodos de evolución llamados inferior, medio y superior. Esta teoría, que fue reconocida como universal, y vendió la idea de una historia de la humanidad vertical, que iba de lo más "primitivo" a lo más civilizado, y donde se entendía que lo primitivo era todo tipo de vida, y de fenotipos diferentes a los europeos; por tanto, lo civilizado y el fin de toda sociedad era ser o reproducir las prácticas y los estilos de vida occidentales. La teoría de Morgan, sirvió entre otras cosas, para justificar presupuestos colonialistas, racistas de superioridad de la gente blanca y de la civilización occidental, pues a menudo se confundía con el "darwinismo social" lo cual era utilizado para combatir culturas distintas y hacer "apología del imperialismo"2.

\footnotetext{
${ }^{2}$ G. Luévano Bustamante, "Sociedad Antigua, Derecho Antiguo. Los orígenes de la Antropología jurídica", en Maine y Morgan. Rosillo Martínez, Alejandro, Estudios jurídico-políticos en homenaje al profesor Eligio Ricavar Sánchez, San Luis Potosí, UASLP, 2007.
} 
En consecuencia, esta idea se universalizo, y a partir de ella se desarrolló toda una primera línea de antropólogos de lo diferente, con la responsabilidad más que nada académica e institucional de darle sentido y argumento a esa lógica evolucionista de la humanidad. Para los casos latinoamericanos, esa lógica fue llevada a las ideas de Homogeneidad ciudadana, y la idea de blanqueamiento de la sociedad, que desarrollaron los Estados independientes que no reconocieron la diversidad de castas y de pobladores que dejo consigo la época Colonial. No hay que dejar de lado, además, que no solo fue una presencia teórica y filosófica la que acompaño los primeros pasos de la antropología en nuestros territorios, es importante resaltar, que los primeros que ejercieron esta labor en la América de mediados del siglo XIX fueron los exploradores y antropólogos europeos, esta sin duda, fue la base y la razón por la cual todos los primeros estudios antropológicos de nuestros países están montados en una base eurocéntrica y evolucionista.

\section{Inicios de la antropología en Colombia, la idea multiculturalista y la reinvención de la Sierra Nevada de Santa Marta}

Uno de los trabajos más completos, que se han elaborado en Colombia con relación a los orígenes y las prácticas antropológicas, es el de los investigadores: Eduardo Restrepo, Victoria Uribe y Ana María Victoria Uribe, en su texto "Antropologías transeúntes" describen a la perfección lo que ha sido y sigue siendo parte de la antropología colombiana. Es por ello, que para dar la introducción a la función antropológica en Colombia, haremos uso de varias de las ideas que estos autores plasman en su libro. Para Restrepo, Las nacientes generaciones de antropólogos son cada vez más distantes de un ejercicio disciplinar que hasta hace solo unos años constituyo el modelo dominante desde el cual se entendió la práctica antropológica. Por tanto, hasta hace solo dos décadas, un antropólogo era asociado a ciertas temáticas y poblaciones más que otras. El estudio del parentesco, del ritual o del mito aparecía como el problema antropológico por antonomasia, en las denominadas ciencias sociales o humanas, y como se dijo al inicio del trabajo, ninguna estaba más cerca a las comunidades indígenas y campesinas que la antropología. Por consiguiente, lo que significaba en términos académicos y políticos hacer antropología en Colombia, era la que se relacionaba con una antropología políticamente comprometida con las poblaciones con las cuales el antropólogo trabajaba, aunque también la relacionaban con una disciplina objetiva, incluso se refería con el hecho de instrumentalizar una antropología militante con las justas cusas de las poblaciones explotadas, al estilo de las ciencias positivas.

Pero ese estilo antropológico, no fue único en Colombia, fue una especie de común denominador que sacudió a toda Americalatina, como veremos más adelante haciendo referencia al caso Mexicano. En Colombia, se dio un proyecto antropológico anclado en el "primitivo", este proyecto ha sido señalado como antropología institucional euroestadounidense y ocupo su lugar en la geografía de las ciencias positivas al retomar para si las 
"sociedades primitivas" que no estaban en la agenda oficial de otras disciplinas como la sociología o la historia. En este contexto, la "complejidad" de lo "primitivo" y la superposición de la "civilización" constituyeron el ámbito de indagación privilegiado de las tempranas generaciones de antropólogos de las metrópolis ${ }^{3}$. Este proyecto tuvo la visión de un primitivo a ser descrito, narrado, historiado, utilizado e instrumentalizado al servicio de un proyecto nación; en su inmensa mayoría un proyecto disciplinar desde afuera, pues era desde las perspectivas eurocéntricas que se le daría legitimidad o no a dicho proyecto, y a sus actores investigados.

Es así como se da esa relación eurocéntrica entre lo que estaba siendo el fortalecimiento de una de las disciplinas más importante del momento, y las relaciones políticas, económicas y culturales entre "el centro y la periferia del mundo"; entre lo que se entendía como países hegemónicos, civilizados, de derechos y de un desarrollo en crecimiento (Estados Unidos, países europeos) y las periferias, ubicadas geográficamente entre África, Asia y Americalatina. Dentro de esta relación creciente, no podemos perder de contexto el hecho de que, fueron las primeras descripciones, clasificaciones y relaciones de los habitantes latinoamericanos con sus gobernantes, quienes sentaron las bases para el interés de América con un sector atractivo a la inversión extranjera, la extracción de materias primas, el ecodesarrollo, el ecoturismo, y todas esas líneas económicas que empezaron a conectar más allá de lo económico y de lo político a estos territorios. Es un análisis filosófico de la modernidad, que lleva a una forma política, una forma política del sistema económico de capital; todo en este sistema de cosas va enlazado, y la antropología cumplía en ese momento un espacio clave.

Es por ello, que se habla de la antropología como un proyecto, inclusive como una empresa, en tanto proyecto implicaba unas relaciones de carácter colonial; de allí, de ese interés, se entiende que se diera el cimiento de la empresa antropológica, nacida en las entrañas mismas del orden colonial y de la expansión del capital. La antropología institucional de las metrópolis ha sido en gran parte la normalización epistémica del imaginario occidental del "primitivo", la domesticación del "salvaje" mediante su racionalización. En Colombia, la antropología ha sido en gran parte y sobre todo en sus comienzos, constituida por la producción de lo "Indio" lo que algunos autores denominan la "indiologizacion" de la antropología. La "Indilogización" de la antropología, más que su énfasis en ciertas poblaciones, es el efecto epistémico y político de la producción de lo "indio" como otredad esencial y como una alteridad radical, no obstante, su apariencia de caos o sinsentido, respondía a un cuidadoso ordenamiento intrínseco al cual se plegaban ineluctablemente los sujetos.

\footnotetext{
${ }^{3}$ John Comaroff y Jean Comaroff, Ethnography and the Historical Imagination. Studies in the Ethnographic Imagination, Chicago, Westview Press, 1992, 12.
} 
El uso de lo "indio" como se plantea en varios trabajos, es un uso que atraviesa lo epistémico, disciplinar e indiscutiblemente lo institucional y constituyente. cuando se habla de los avances constitucionales a favor de los pueblos originarios en América Latina, siempre se hace referencia a Colombia, ya que fue uno de los primeros países en declarar en la Constitución de 1991 su condición multiétnica y pluricultural; dentro de esta misma legislación, se le dio a la comunidades un reconocimiento diferencial, se le brindaron herramientas de protección, participación política, reconocimiento territorial, a partir de las figuras de los resguardos y se consolido, para los pueblos indígenas de Santa Marta, la protección de la Línea Negra (espacios sagrados intocables, de interés nacional cultural). En conclusión, con la constitución, y con la visibilización de los pueblos indígenas como actores sociales y económicos, se emprendió el camino de la multiinstitucionalidad y se puso en marcha el proyecto multicultural en Colombia.

El proyecto multicultural, va de la mano de un contexto social y económico que se venía consolidando desde finales del siglo XIX, en el que los estados habían empleado herramientas y disciplinas académicas y científicas, que les permitieron saber ¿en qué condiciones poblacionales, territoriales y económicas se encontraban?, ¿con que recursos se podía trabajar? ¿Qué se necesitaba para hacer de esas nacientes naciones, países económicamente activos y de inversión global?, y ¿cómo hacer posible la incorporación de las poblaciones no occidentalizadas y nacionales a la vida y estructura de las economías nacionales? Teniendo en cuenta, que las poblaciones indígenas, se mantuvieron aisladas del control en su momento colonial, y después republicano, no era fácil acceder a ellas, eran resistentes, autosuficientes, y nunca han estado dispuestas a darse por vencidas, ya tenían experiencia en la lucha y en la resistencia, lo habían hecho desde hacía tres siglos atrás. La respuesta estatal a esas condiciones diferenciales de sus pobladores fue inicialmente violenta: arremetidas militares, misiones capuchinas, catolización de la población, restricciones del libre tránsito, intervención territorial, inversión y promoción de llegada de colonos a zonas indígenas, para promover el mestizaje, etcétera. Si bien, algunas de estas tácticas, dieron resultado, no se logró tener control ni acceso absoluto a esos espacios, ni a sus habitantes, ni a sus recursos, el Estado Colombiano aun hoy día sigue sin hacer presencia en muchos territorios colombianos, especialmente de presencia indígena y afrodescendiente. No obstante, con las herramientas y el conocimiento que de las comunidades se obtuvieron a partir de la antropología y otras disciplinas, el Estado Colombiano encontró en el multiculturalismo la forma legal de acceder social, poblacional, territorial y económicamente a las zonas campesinas e indígenas; y de la mano de los intereses transnacionales de la economía, llego el dialogo interétnico e interinstitucional del multiculturalismo.

Como bien lo explica Carlos Duarte, El rostro neoliberal de la etnicidad institucionalizada por el Estado Colombiano se expresa, en su mayor 
dimensión, cuando las subjetividades comunitarias se formalizan y, en medio de las coyunturas de resistencia y movilización étnica, el Estado privilegia los intereses del mercado. Dentro de estos privilegios, el multiculturalismo es un pacto, es una estrategia del neoliberalismo, en la que se tiene una tendencia a producir una poderosa dinámica de re-etnizacion estratégica en contextos urbanos y rurales, con el fin de acceder a las ciudadanías multiculturales. Las políticas multiculturales, que quizás definen mejor su pretensión neoindigenista, es la necesidad de construir, en medio de la diversidad étnica y cultural, un interlocutor homogeneizado y debidamente territorializado; para realizar este objetivo, el Estado multicultural se ha visto en la obligación de implementar diversos mecanismos para reconocer una etnicidad institucionalizada. Todo ello, permite crear algunas categorías más relevantes como una concepción homogeneizada del territorio y de la autoridad étnica ${ }^{4}$.

En concordancia con lo anterior, es muy importante analizar las implicaciones del enfoque multicultural en el contexto colombiano, y como este ha contribuido a la construcción de una categoría esencialista, estática y ecologista de etnicidad, de asistencialismo institucional; que dejan por fuera las complejas relaciones que se generan dentro de la multiculturalidad. El discurso multiculturalista ha invisibilizado los procesos diferenciales, ha dado por ciertos y únicos las interpretaciones que desde lo institucional o académico se tienen de las comunidades étnicamente diferenciadas, ya que estas comunidades no han sido incluidas dentro de ese discurso, dentro de esas "verdades conceptuales" y "descriptivas"; de hecho, bajo el amparo multiculturalista, se ha generado una idea generalizada de lo que es ser indígena en Colombia, de lo indígena como algo homogéneo, del indígena como ser ecológico. Colombia tiene más de 102 comunidades indígenas, y cada una de esas comunidades responden a entornos de vida diferentes entre sí, a luchas diferentes, a concepciones de lo espiritual, cultural económico y social diferentes, a relaciones con la institucionalidad particulares, por tanto, crear la idea del indígena hegemónico y característico colombiano, es seguir cayendo en las trampas del multiculturalismo estatal y funcional.

\section{La reconfiguración conceptual y territorial de la Sierra}

Casi todos los trabajos que investigan la Sierra Nevada de Santa Marta, desde diferentes disciplinas y problemáticas, usan o mantienen una concepción de la misma, amparada en los primeros discursos antropológicos e institucionales que de ella se hicieron y que se han ido adaptando a las necesidades, imaginarios y funcionalidad del territorio. Una de las definiciones que más encontramos y la única que aparece al googlear dicho territorio es la siguiente: La Sierra Nevada de Santa Marta (SNSM) es el sistema montañoso litoral más alto del planeta; ubicado al norte de Colombia que constituye por sí mismo un sistema aislado de los Andes, sobre la costa

\footnotetext{
${ }^{4}$ C. A. Duarte, "Los macromodelos de la gobernanza indígena colombiana: un análisis socioespacial a los conflictos territoriales del multiculturalismo operativo colombiano". Maguaré, 29, 1, 2015, 181-234.
} 
Caribe de Colombia. La UNESCO la declaró Reserva de la Biosfera y Patrimonio de la Humanidad en 1979, dada la red de ecosistemas que albergan innumerables formas de vida y que son hogar de varias comunidades indígenas. Esta imponente montaña ocupa los departamentos del Magdalena, La Guajira y Cesar. La sociedad que habitó esta región, conocida como Tayrona se considera, junto con la Muisca, como una de las grandes civilizaciones precoloniales colombianas, reconocidas históricamente por sus aportes a la ingeniería en caminos en Piedra, conocido ese sistema de construcción como la ciudad perdida, una de las culturas más avanzadas de la América Prehispánica ${ }^{5}$.

En esta definición se muestran las metáforas para crear la Sierra como objeto de conocimiento, como un territorio con una alta complejidad político administrativa en relación a los diferentes sistemas de gobierno que en ella tienen lugar (departamentos-municipios y resguardos) y, por otro, las categorías de reserva forestal, reserva de la biosfera, resguardo y área protegida (parque nacional natural).

La sierra es vista desde las nociones de "territorios salvajes, fronteras y tierras de nadie" propuesto por Margarita serie en el libro El revés de la nación, en donde las zonas periféricas han sido construidas desde dos representaciones que estructuran las relaciones con estos territorios ${ }^{6}$. En pocas palabras, es un territorio construido bajo miradas descriptivas de tipo geográfico, natural, espacial, económico y cultural. Por otro lado, también encontramos en la SNSM, descripciones con pretensiones de objetividad que se han dado a la tarea de describir el territorio desde los lentes de la ciencia occidental:

La Sierra Nevada es un macizo montañoso aislado de la cordillera de los andes situado al norte de la república de Colombia [...] El flanco norte bordea el Mar Caribe desde las tierras planas y áridas del sur de la península de la Guajira hasta los alrededores de Santa Marta, en la desembocadura del rio manzanares; el flanco occidental limita con el mar Caribe, la Ciénaga Grande de Santa Marta y la planicie aluvial del rio Magdalena, desde la desembocadura del rio Manzanares hasta la población de Bosconia"7.

Estas son solo algunas de las definiciones que se le han dado, y se le siguen dando a la Sierra, todas apuntando a las mismas características. Lo que evidenciamos en estas comparativas, es que existe un conflicto amplio en la descripción que se tiene de la Sierra. Dicho conflicto tiene que ver con la homogenización conceptual que desde la academia se le ha dado al territorio, dejando por fuera la descripción que de ella tienen los pueblos originarios que la han habitado por miles de años. Las descripciones y delimitaciones

\footnotetext{
${ }^{5}$ M. Serje, "La invención de la Sierra Nevada". Antípoda. Revista de Antropología y Arqueología, 7, 2008, $197-229$.

${ }^{6}$ L. Aja Eslava, "Agua, territorio y poder: representaciones, significados, usos y manejos del agua en la Sierra Nevada de Santa Marta, Estudio de Caso./Water, territory and power: representations, meanings and uses of water in the Sierra Nevada de Santa Marta, case study handles”. Instituto de Estudios Caribeños, 2010.

${ }^{7}$ ¿Qué es la Sierra?, consultado en: http://www.colparques.net/SIERRA. 27 de abril del 2020.
} 
tradicionales de la Sierra pasan por describir su fisiografía, geología, clima, hidrología, biogeografía, biomas, flora, fauna, aspectos socioeconómicos y culturales, régimen administrativo y político; análisis de dimensiones y la descripción de contextos. Mientras que el lenguaje y el sistema de representación indígena conciben a la sierra como "el corazón del mundo"; un corazón que está regido por la Ley de Origen o Ley de Sé.

Esta ley rige la vida y el conocimiento espiritual, y su función es mantener el orden del universo y el territorio. Además, establece las leyes para que los cuatro pueblos puedan vivir en armonía; para ello, se centra en la recolección de aspectos relacionados con la identidad cultural, con lo espiritual y material del territorio y sus habitantes. Por consiguiente, la ley de origen es la garante del equilibrio y permanencia del territorio. En este contexto, es que se desenvuelve toda la historia y funcionamiento de las comunidades indígenas de la Sierra; y la misión de los cuatro pueblos (Arhuacos, Koguis, Wiwas y Kankuamos) es mantener el orden y el equilibrio del territorio y del universo, a través de los pagamentos de todo cuanto existe: arboles, agua, piedra, lluvia, atmósfera, laguna, etc. Dicha ley se transforma en un compromiso espiritual fundamentado en el pensamiento ${ }^{8}$.

Por poner solo un ejemplo, de concepción propia del territorio, desde la Sierra Nevada de Santa Marta, tenemos el caso de la comunidad de la Zona indígena de Nabusímake, quienes reconocen que el territorio fue ordenado en el momento en que los padres espirituales lo crearon. De igual modo, afirman, que en la creación determinaron el lugar que cada ser o cosa debe ocupar, como los ríos, los cerros, las piedras, y las plantas; y también establecieron las normas o leyes que el indígena debe cumplir para relacionarse en armonía con estos elementos. Al respecto afirma Navarro Carrascal, que "en el entendimiento de las normas contenidas en el territorio, es indispensable el saber por qué cada ser existe en un sitio determinado, dónde se encuentran esos sitios y para qué están ahí los individuos de todas las especies, los cerros, las lagunas, las piedras. Es una muestran de cómo se organiza el territorio". . En esta concepción propia del territorio desde lo indígena, entendemos que más que una descripción de la tierra, se hace una descripción de la misma con lo espiritual, con lo cultural y con la cosmogonía de todo cuanto hace parte del territorio y de quienes lo habitan.

Las características de construcción del territorio de la Sierra Nevada aquí dadas, son explicadas dentro de su funcionalidad por Astrid Ulloa, quien explica que esta construcción se da a partir de dos nociones; la primera es la noción monista, que plantea la idea de integralidad e interrelación con la naturaleza; y la segunda es la noción dualista, desde la oposición naturaleza y sociedad, esta última noción deriva hacia el desarrollo sostenible y la biodiversidad. Estas dos nociones las encontramos en los discursos para

\footnotetext{
${ }^{8}$ Organización Indígena Kankuama, Los mayores: autoridades del pueblo Kankuamo. Bogotá. 2010.

${ }^{9}$ R. C. Niño Izquierdo, Organización y uso del territorio por la comunidad Indígena Arhuaca de Nabusímake Sierra Nevada de Santa Marta (Colombia), 2011.
} 
definir y delimitar la Sierra como objeto de conservación, de explotación, de Ordenamiento o de Paz. Pero este, no lo podemos ver solo como un problema académico, sino que es un problema político sobre el cual se discute, se organiza el poder y se construyen las subjetividades de diversos pueblos. Dentro de este marco contextual, se explica dentro de la Sierra, el surgimiento de la conciencia ambiental, como problema global; el surgimiento del ambientalismo como campo de saber-poder que transformo diferentes disciplinas (sociales y naturales) y los procesos de construcción de conocimientos expertos dentro de la delimitación de los territorios ${ }^{10}$. Por ende, la Sierra es el reflejo de una política indigenista que como bien hemos sustentado, iba de la mano de una agenda de competitividad regional, que utilizo la descripción e incorporación del territorio para avanzar y hacer posible la implementación de megaproyectos de infraestructura e inversión extranjera, que inicialmente se escondieron bajo la figura de protección ambiental y salvaguarda territorial y expansión del espacio territorial (ampliación de los resguardos).

Uno de los primeros estudios que cambio la forma en la que el Estado y el exterior vio la Sierra Nevada de Santa Marta, fue el del Francés Joseph De Brettes, posteriormente, se sumaron los de los exploradores, científicos y viajeros europeos que impulsaron una nueva mirada sobre la Sierra: como una frontera ya no tan inhóspita, sino con incalculables medios para impulsar el progreso de la región por los desconocidos recursos y posibilidades que la montaña brindaba, siempre y cuando estuviera ocupada por poblaciones prociviles a la explotación de los recursos para la exportación de materia prima y la acumulación de capital. Todo ello, bajo la lógica de un Estado Liberal. Es así como se da la política de integración de la Sierra al proyecto nacional, primero la estrategia del reconocimiento, categorización y segundo, fue la Constitución del Territorio de la Nevada y Motilones, a través del cual la administración de la Sierra Nevada paso a depender de Bogotá, en 1875, con este cambio, se impulsó la llegada de colonos europeos (sobre todo de alemanes), para que trajeran nuevos cultivos y actividades productivas que anexaran a la Sierra a las políticas económicas de exportación de materias primas hacia los mercados europeos ${ }^{11}$. Es así como la Sierra se vuelve atractiva a los intereses Transnacionales, de explotación de sus recursos y entra a ser parte de la gran locomotora económica de Colombia.

Así se dio el proceso de incorporación de la Sierra a las economías de mercado y a los procesos globales y nacionales de modernización del país, iniciado a finales del siglo XIX, la incorporación de la Sierra, fue una estrategia amparada en el dialogo multiculturalista del Estado colombiano, una idea que además de cambiar la delimitación territorial de La Sierra, cambio el entorno en sí, ya que para garantizar una economía transnacional en la zona, y unas políticas de inversión segura, el Estado hizo lo que nunca

\footnotetext{
${ }^{10}$ A. Ulloa Cubillos, (2004). La construcción del nativo ecológico: complejidades, paradojas y dilemas de la relación entre los movimientos indígenas y el ambientalismo en Colombia. Bogotá, 2004.

${ }^{11}$ L. Aja Eslava, "Agua, territorio y poder".
} 
debió hacer, agravar los problemas de violencia territorial en la zona, con la presencia de militares y la creación de batallones dentro de territorio indígena; bajo la percepción de seguridad en la región, el Estado vendió esta protección, como salvaguarda del patrimonio, de los recursos y de la conservación de nuestra diversidad cultural y étnica; pero sabemos que las consecuencias y las razones de esa intervención militar fueron otras.

Bajo las visiones aquí planteadas de la Sierra, el Estado hizo presencia por primera vez en el territorio, a través del Proyecto cordón ambiental y tradicional de la Sierra Nevada de Santa Marta, como estrategia de control civicomilitar del territorio, en el marco de la política de defensa y seguridad democrática. Esto, bajo una noción de "recuperación social del territorio", que se da a partir del 2004; la intervención fue la respuesta gubernamental para superar la crisis humanitaria de la Sierra (presencia guerrillera, paramilitar, cultivos ilícitos, contrabando) y el abandono estatal. De esta manera, no solo se daba la sensación de apoyo y protección estatal, sino que, se quiso potencializar el desarrollo al garantizar la inversión a través de la seguridad, y poner al servicio de la lógica económica y territorial del gobierno estos asentamientos. Para el año 2004, el gobierno de Álvaro Uribe, inicio la estrategia de intervención territorial para superar la crisis humanitaria de la Sierra nevada de Santa Marta. Para este año, las comunidades indígenas Kogui, Wiwa, Arhuaca y Kankuama y de los colonos que habitan en la Sierra Nevada de Santa Marta, provenientes de los departamentos de Santander, Boyacá, Tolima y Antioquia, presentaron ante la Comisión de Derechos Humanos, esta intervención como "una grave y masiva violación de los derechos humanos, y expusieron la sistemática infracción a las normas del Derecho Internacional Humanitario de los actores armados del conflicto y la falta de presencia real y efectiva del Estado ${ }^{12}$.

Estado, con las ideas de protección y vida de los indígenas; pero sabemos que en el fondo respondiendo a medias que consideramos pañitos de agua tibia, ante lo que deberían ser las reales y eficientes intervenciones gubernamentales y estatales en la zona. Pues no podemos perder de vista el hecho de que, bajo las distintas dinámicas del conflicto en relación a los actores con presencia en la SNSM y los factores que inciden en la protección ambiental, encontramos la presencia de cultivo ilícitos y las fumigaciones como método de erradicación, la confrontación armada y la presencia de grupos paramilitares y guerrilleros, así como la presencia y acción del Batallón 6 de Alta montaña; todos estos factores de intervención legal e ilegal hacen su propia utilización y control social del territorio, generando una afectación constante e interna de los derechos colectivos de las comunidades indígenas ${ }^{13}$. Lo más dramático de todas está intervenciones en el territorio, es que la autonomía y la autodeficion y control territorial de las comunidades

\footnotetext{
${ }^{12}$ L. Munera, "Pueblos indígenas, control territorial y desarrollo. El caso de la Sierra Nevada de Santa Marta". Cien días vistos por CINEP, 66, 2009.

${ }^{13}$ S. Holguín Bustos, Conflicto Armado Y Medio Ambiente: Tensiones En El Derecho, Intereses Y Actores. El Caso De La Sierra Nevada De Santa Marta. Diss. Universidad Industrial de Santander, Escuela de Derecho y Ciencia Política, 2017.
} 
indígenas, terminan siendo nulas o inexistentes, generando con esto una triple violencia estructural del territorio.

La ruptura multiinstitucional y la pugna intra e interétnica por la tierra genero apuestas de intervención por parte de todos los actores legales e ilegales, los indígenas luchaban y defendían su noción de territorio, los que se veían muy expuesto a los conflictos seguían subiendo y subiendo la Sierra, para de esta forma alejarse de los colonos y de los demás indígenas que si se acogieron a las medidas de intercambio administrativo y ambiental con el Estado; pues la presencia militar, genero más desconfianza y miedo a más represiones: se presentaron desapariciones de líderes sociales y espirituales, desapariciones forzosas, desplazamiento y asesinatos selectivos y sistemáticos, así como lo que los colombianos llamamos "falsos positivos". Por su parte, los indígenas que se sometieron al dialogo multinstitucional y con ello a los proyectos ecológicos de "Pro Sierra", quedaron sometidos a una idea abstraída del indígena en los territorios. El Estado y la figura de Parques Nacionales y Naturales de Colombia, sustento en un discurso ecologista de la conservación, la presencia del indígena como un nativo civil, en sus documentos administrativos, que son de uso público, se puede identificar una conceptualización de la población indígena como componente natural de los paisajes prístino de la Sierra Nevada de Santa Marta, y la interpretación de sus prácticas económicas y rituales como afines a la conservación del medio ambiente. No obstante, esto implica la aceptación táctica de su carácter originario y del imaginario del "buen salvaje", protector del medio ambiente. Por ello, a pesar de que el Estado pretendió reivindicar a través del multiculturalismo la diversidad étnica y la necesidad de proteger al medio ambiente, lo que hizo fue agrandar más las brechas que suprimen esa diversidad, al construir sujetos de derechos estáticos, sin oportunidades de cambio e idealizados a las comunidades (el buen salvaje o el indígena ecológico) y al excluir de este panorama de la alteridad a otros imaginarios y marginados que han sufrido procesos de expropiación y no reconocimientos ${ }^{14}$.

Dentro de todos los cambios conceptuales y territoriales aquí analizados, podemos empezar a concluir que el multiculturalismo en Colombia está lleno de paradojas y de irregularidades dentro de su praxis y dentro de su práctica. Diana Bocarejo, por ejemplo, plantea que, los derechos diferenciales dentro del reconocimiento de la diversidad, tienen que ver con los arreglos políticos del multiculturalismo en Colombia, y lo primero es la forma como se especializa la diferencia indígena y como a través de ella se examinan sus implicaciones políticas. Para Bocarejo, el multiculturalismo colombiano presenta dos paradojas; la primera, es la forma como se juzga a quien es o no es un sujeto indígena, utilizando como eje, las características dominantes, su noción, de naturaleza, de protector del medio ambiente y su condición de

${ }^{14}$ D. R. Osorio, "Consensos, conflictos y ambigüedades en torno al territorio: exploración etnohistórica de la lengüeta, Sierra Nevada de Santa Marta". Maguaré, 32, 1, 20188, 171-204. 
indígena a partir del hecho, de que este debe vivir en un resguardo "rural" de reconocimiento Estatal. La segunda paradoja, tiene que ver con el aislamiento político y autorepresentativo de las propias comunidades indígenas, para que podamos hablar de un verdadero dialogo interétnico y multicultural ${ }^{15}$. Todo esto, nos lleva a pensar que en Colombia el multiculturalismo es una ilusión política difundida en el centro de las democracias liberales contemporáneas, amparadas en políticas de violencia "legal", todo amparado en un Estado, en unas políticas y en una constitución fetichizada, donde el gobierno soberano creé ser la sede del poder, y la comunidad política lo acepta.

Teniendo en cuenta los planteamientos aquí expuestos, podemos afirmar que los actuales conflictos que se están presentado entre los pueblos originarios en Colombia y el Estado, obedecen a una falla estructural de negación de la negación, a partir de la manera como se fuerza y se contrapone una idea y una visión de vida contra otra, a la forma como el dialogo intercultural que empezó con el multiculturalismo, nunca se dio de la manera como se creyó. Si nos vamos al contexto de la Sierra Nevada de Santa Marta, encontramos que, los cuatro pueblos de la Sierra han venido trabajando en sus "planes propios" y sus "planes culturales" para la consolidación de instrumentos de salvaguarda étnica, en el marco de un proceso de negociación con el Gobierno Colombiano. Las Organizaciones indígenas de la Sierra: la Organización Gonawindua Tayrona-OGT-, la Organización Wiwa Yugumaiun-OWY-, la Confederación Indígena Tayrona -CIT-, y la organización Indígena Kankuama-OIK- todas estas han venido trabajando conjuntamente, a través del Consejo Territorial de Cabildos ${ }^{16}$. Los pueblos de la Sierra, para buscar dialogar de tú a tú con el Estado, no bajo una mirada proteccionista ni asistencialista, sino, bajo unas miradas claras de diferenciación cultural y social. En consecuencia, los indígenas también han desarrollado, con alianza de colectivos jurídicos y otras organizaciones sociales, redes de defensa de los derechos humanos de los pueblos indígenas y prácticas de litigio estratégico y de incidencia en política. Estas prácticas constituyen lo que algunos expertos han denominado los "procesos de judicialización de la política" y los procesos de normativas diferenciales, donde se apela a un multiculturalismo eficiente.

Dentro de esta discusión y estas nuevas labores o interés antropológicos, es que se deben sustentar los actuales trabajos de esta disciplina, desde la mirada diferencial, y desde el dialogo entre la normativa estatal, gubernamental y la nativa o leyes de las poblaciones aborígenes. Esto, entre otras cosas, porque la antropología es percibida directamente como algo involucrado en asuntos de política pública o de proyectos de desarrollo. En este aspecto, y para ser más específicos, citaremos las palabras de Alexnadra Ángelo, quien nos ejemplifica, que en los años posteriores a la segunda guerra mundial, un

\footnotetext{
${ }^{15}$ D. Bocarejo, "Dos paradojas del multiculturalismo colombiano: la espacialización de la diferencia indígena y su aislamiento político". Revista Colombiana de Antropología, 47, 2, 2011, pp. 97-121.

${ }^{16}$ G. A. Rodríguez, G. A., y A. Mora Rodriguez, (2010). Conflictos y judicialización de la política en la Sierra Nevada de Santa Marta. Editorial Universidad del Rosario, 2010.
} 
ámbito clave en el cual la antropología ha tenido un papel importante por su colaboración con administraciones y entidades públicas ha sido el de la cooperación internacional y los proyectos de desarrollo. La cooperación internacional nació en el contexto histórico-político de los años cincuenta, y su origen fue guiado por la voluntad de Estados Unidos de entregar ayudas a una Europa inestable a través del Plan Marshall del gobierno Truman, en 1948. Posteriormente a partir de los años sesenta, es que la antropología tuvo un papel cada vez más importante dentro de este proceso, y a partir de los setenta se dio "una transformación significativa en el concepto de desarrollo, trayendo a primer plano los factores sociales y culturales de los proyectos". Por este motivo, paulatinamente se llegó a institucionalizar el papel de los antropólogos ${ }^{17}$. El papel de la antropología, es de generar conocimiento, trasmitir saberes dejando de lado la colonialidad del saber y del poder, y con ello generar transformaciones, dichas transformaciones y aportes serán fundamentales para los actores y pueblos con los que trabaja, no hablando de ellos, sino hablando con ellos, no de desarrollo sino de desarrollos; la idea única e inequívoca de desarrollo es más que nunca obsoleta.

El concepto de desarrollo, ha llevado a muchas ciencias sociales a delimitar las formas en las que se organiza la vida social, dando la sensación de necesidad que hay en el mundo de darle clasificación a todo, por eso, el mundo se ha organizado más que en aspectos culturales y diferenciales, según el contexto y las necesidades políticas y económicas de la época. Para el caso de la Sierra Nevada, las diferentes formas de categorización espacial que se les han dado desde la antropologia y otras ciencias, ha determinado una forma específica de conocimiento de la misma, que a su vez han generado unas prácticas de acción institucionales que han ido en contra de lo que en sí quiere y necesita el territorio y las comunidades. Por otro lado, en el ámbito del discurso ambiental en la Sierra, es importante tener en cuenta la forma en que estos discursos ambientales generan la "construcción de una geografía" especifica, que delimita tanto lo que se considera Parque Nacional como lo que se considera territorio indígena, así como quienes se encuentran dentro de estos territorios y quiénes no. Por tanto, la preocupación por el orden, la conformidad y la homogeneidad social, lleva en este caso a la instauración de un espacio ambiguo y de difícil definición que se materializa como un espacio de negociación. Esto se puede ver reflejado en algunos discursos indígenas actuales, en los cuales articulan conceptos y nociones occidentales a sus discursos ancestrales, para posicionarlos a nivel nacional e internacional $^{18}$.

La responsabilidad de las disciplinas sociales, recae en lo que dichos estudios representan tanto para las comunidades investigadas, como para las normas y prácticas de políticas públicas y económicas que de ellas se harán con base a lo que se entienda de ellas. Es por ello, que debemos rescatar las labores reales

\footnotetext{
${ }^{17}$ A. D'Angelo," Restituir las tierras en el marco del post-conflicto colombiano: una mirada al caso indígena Wiwa de la Sierra Nevada de Santa Marta". Perifèria: revista de recerca i formació en antropologia, 22, 2, 2017, 112-135.

${ }^{18}$ Lina Peralta Casas, "Categorías espaciales con relación al medio ambiente en la Sierra Nevada de Santa Marta".
} 
de darle contexto, historia y voz a los actores sociales, de no ser los investigadores que solo extraen información; por tanto, es necesario que al igual que como la antropología se ha reinventado, el trabajo interdisciplinar tenga una visión de dialogo horizontal. En palabras de Margarita Serje, concluimos que dentro de esta dinámica y responsabilidad disciplinaria, la Sierra ha sido definida de una forma funcionalista y evolucionista; en la que los esfuerzos por definir el paisaje como objeto antropológico, parten de naturalizar y universalizar la relación epistemológica que hizo lo posible en occidente, es decir la relación entre un sujeto contemplativo y un objetonaturaleza, mediada por unos esquemas. Así, el observador abstrae una porción de la superficie terrestre, arrancándola de su continuidad históricogeográfica para situarla en un nuevo contexto (en el de la ciencia o en el de la estética). La antropología se ha preocupado por reconocer esa continuidad histórico geográfica, es decir, por recoger el "punto de vista del nativo" de los paisajes estudiados. Ha presumido, sin embargo, que se trata de un punto de vista a partir del cual se crea un paisaje. Dicho en otras palabras, se supone la existencia de un paisaje autónomo que se subordina a una mirada que lo abarca, proyectando así los supuestos de la oposición occidental naturalezacultura a la relación que otras sociedades establecen con sus entornos ${ }^{19}$.

De la labor antropológica de las comunidades indígenas, dependerá la aceptación o el imaginario que de ella se hagan las personas externas, sabrán como viven, como expresan lo territorial, como piensan y se piensan en el Estado, se darán respuesta a una serie de preguntas, acordes a cada investigación, pero que tendrá repercusiones en diferentes sentidos, locales (las comunidades) institucionales (el Estado) y sociales (los ciudadanos mestizos). Es por ello, que las descripciones e imaginarios que se hacen de un territorio o comunidad tiene que ser analizadas bajo contextos que parten de lo particular a lo general, y donde cada factor va a estar intrínsecamente interconectado. Las comunidades negras e indígenas nunca han parado la producción de conceptos propios, de derechos humanos, de autonomía, de institucionalidad y gobernanza; solo que su lucha y saberes no entraban en la concepción eurocéntrica occidentalizada de los derechos humanos, por tanto son invisivilizados, ocultados, y muchas veces transformado de forma funcionalista y utilitarista.

Lo que vimos en la descripción e incorporación territorial de la Sierra a los interés nacionales, es una incorporación desde una visión de Estado unitario, donde el territorio, los habitantes del mismo y sus relaciones, son entendida, clasificadas y conceptualizadas bajo unos parámetros desiguales y hegemónicos, que impiden el dialogo intercultural y la eficiente noción de naciones multiculturales. Esto, entre otras cosas, porque se sigue hablando de la multiculturalidad desde una visión legal de aculturación y despojo territorial, amparada en derechos y normas positivistas que ocultan y reprimen los saberes propios de las comunidades indígenas, en palabras de

${ }^{19}$ M. Serje, "La invención de la Sierra Nevada". 
Adonon viveros, se considera que las falencias en la relación que se está dando entre multiculturalismo, estado y derechos, es el resultado de la mala incorporación académica e institucional de la diferencia cultural.

La problemática que se teje en el seno del Estado, del derecho y del multiculturalismo, es la compleja dinámica que se produce como resultado de las imposiciones hegemónicas y las resistencias identitarias. Pero estas problemáticas, no son únicas del caso colombiano; cuando en México se abordó la multiculturalidad, como en muchos países latinoamericanos, se hizo bajo la misma idea de homogenización cultural, social y territorial, como consecuencia de ello, en México no se hablaban ni de indígenas, ni mucho menos de afromexicanos, todos entraron en la clasificación de ciudadanos, todos entraron en las practicas desde la norma, del Estado Nación, esto género, un fuerte impacto en las concepciones culturales y sociales de las comunidades indígenas, así como en las percepciones que de los mismos se tenían por parte del resto de la población, que si se consideraba no como indígenas, sino como ciudadanos nacientes de la independencia. Por tanto, los referentes sociales e institucionales de diferentes mundos se deberían cruzar en la práctica de los actores, generando una coexistencia sorprendente entre ellos. Pero no siendo así, el derecho positivo fue el instrumento privilegiado para darle fundamento a la única identidad cultural buscada- que era la del ciudadano mexicano ${ }^{20}$. Como diría Viveros, se violentó la idea diferencial a partir de la unión unilateral y homogénea de las culturas y de las instituciones que las "representan" o las deberían representar dentro del multiculturalismo.

\section{Conclusiones}

La antropología siempre se ha preguntado ¿Cómo aprender y como construir los mundos? ¿Cómo cambian las construcciones que de ellos se hacen? ¿Cómo documentamos dichos cambios? ¿Cómo posicionamos esas miradas y los resultados que se obtienen? Todas estas preguntas son la historia misma del que hacer y de la responsabilidad antropológica, porque siempre se parte de posicionamientos situados, por tanto no hay una antropología puramente descriptiva, se dan variables y contradicciones dentro de la misma antropología. Para la temática aquí estudiada, vimos cómo se construye el valor de las cosas, de los territorios, del otro, de sus prácticas y de sus comportamientos y creencias; todo este proceso nos lleva a cuestionarnos ¿qué entendemos por igualdad, desigualdad, otros modelos de desarrollo y modelos de vida contra hegemónica? ¿Cómo entendemos y trabajamos el multiculturalismo y su implementación?, todas estas, son preguntas abiertas que quedan en medio de un tema poco estudiado en Colombia, debido a las fibras que mueve.

Es importante resaltar el breve análisis que se hizo de la relación entre antropología y derecho, poniendo de manifiesto los reclamos desde los

\footnotetext{
${ }^{20}$ A. Adonon Viveros, "Estado, derecho y multiculturalismo: Un enfoque de antropología jurídica en México". Nueva antropología, 22, 71, 2009, 51-72.
} 
pueblos originarios que no fueron tenidos en cuenta dentro de la imposición de un modelo normativo homogéneo a una realidad diferente. Tal como lo planteaba Stevenhagen, no hay que perder de vista el vacío que existe entre lo normativo y las prácticas indígenas con relación al mismo. Porque ese vacío nos lleva, en el caso indígena a una violación sistemática de todos los derechos más elementales de los pueblos indígenas, y que hoy día los tiene reclamando su derecho propio. Hoy somos testigos de esa disputa entre el derecho consuetudinaria indígena vs derecho positivo del Estado. En palabras de Malinosky, la ley es parte de un sistema de normas, que no puede abstraerse de la cultura y el poder, y entendemos que al no entender la norma desde esta visión, es que se da la cruzada antropológica contra el etnocentrismo, anclada en un relativismo cultural, que constituyo uno de los más claros puntos de la agenda de antropólogos, aunque para unos significara un compromiso ético con la ciencia y para otros, uno político con los pueblos.

Con el estudio del impacto de la antropología y el multiculturalismo en la Sierra, vimos manifestadas las falencia y problemas que se presenta, al no incorporar de forma crítica y responsable el dialogo cultural y plurietnico. La Sierra, como se plantea en este estudio, fue un ejercicio, una prueba, un experimento del multiculturalismo en Colombia; a través de ella se incorporó una mirada equivoca y coercitiva del territorio y de sus pueblos aborígenes. Un multiculturalismo sostenido bajo las leyes de la constitución de 1991 que construyo la visión de una sociedad recreada culturalmente a partir de unos intereses políticos y económicos de completa violencia institucional. Dentro de este análisis, la Sierra Nevada de Santa Marta, quedo enmarcada en tres espacios: una globalización de localidades catalizadas por el capital filantrópico destinado a la conservación ecológica y étnica, un proceso de inversión económica que cambio su entorno territorial y su papel diferencial dentro del Estado Colombiano, y, por último, dentro de ella, se dieron las dinámicas constituidas por los recursos liberados para las zonas informalizadas, de las cuales se nutren actualmente los negocios transnacionales más rentables, así como el narcotráfico y la guerra de entes estatales, paraestatales y guerrillas.

Hoy día, las comunidades indígenas de la Sierra Nevada de Santa Marta, se han tomado los espacios jurídicos, sociales y culturales, para defender sus posturas propias, hoy hacen uso de las mismas herramientas del Estado para defenderse, para enfrentar los nuevos retos económicos, de desigualdad y de malos conceptos académicos que de ellos se hacen, hoy de la mano de nuevas generaciones de antropólogos, sociólogos, historiadores, etnógrafos, abogados, etcétera, defienden institucional, legal y ancestralmente su visión de mundo y de territorio.

\section{Bibliografía}

Adonon Viveros, A., "Estado, derecho y multiculturalismo: Un enfoque de antropología jurídica en México". Nueva antropología, 22, 71, 2009, 51-72. 
Aja Eslava, L. "Agua, territorio y poder: representaciones, significados, usos y manejos del agua en la Sierra Nevada de Santa Marta, Estudio de Caso./Water, territory and power: representations, meanings and uses of water in the Sierra Nevada de Santa Marta, case study handles". Instituto de Estudios Caribeños, 2010.

Bocarejo, D., "Dos paradojas del multiculturalismo colombiano: la espacialización de la diferencia indígena y su aislamiento político". Revista Colombiana de Antropología, 47, 2, 2011, pp. 97-121.

Comaroff John y Comaroff Jean, Ethnography and the Historical Imagination. Studies in the Ethnographic Imagination, Chicago, Westview Press, 1992.

D'Angelo, A. "Restituir las tierras en el marco del post-conflicto colombiano: una mirada al caso indígena Wiwa de la Sierra Nevada de Santa Marta". Perifèria: revista de recerca i formació en antropologia, 22, 2, 2017, 112-135.

Duarte, C. A., "Los macromodelos de la gobernanza indígena colombiana: un análisis socioespacial a los conflictos territoriales del multiculturalismo operativo colombiano". Maguaré, 29, 1, 2015, 181-234.

Holguín Bustos, S., Conflicto Armado Y Medio Ambiente: Tensiones En El Derecho, Intereses Y Actores. El Caso De La Sierra Nevada De Santa Marta. Diss. Universidad Industrial de Santander, Escuela de Derecho y Ciencia Política, 2017.

Luévano Bustamante, G., "Sociedad Antigua, Derecho Antiguo. Los orígenes de la Antropología jurídica", en Maine y Morgan. Rosillo Martínez, Alejandro, Estudios jurídico-políticos en homenaje al profesor Eligio Ricavar Sánchez, San Luis Potosí, UASLP, 2007.

Munera, L. "Pueblos indígenas, control territorial y desarrollo. El caso de la Sierra Nevada de Santa Marta". Cien días vistos por CINEP, 66, 2009.

Niño Izquierdo, R. C., Organización y uso del territorio por la comunidad Indígena Arhuaca de Nabusímake Sierra Nevada de Santa Marta (Colombia), 2011.

Organización Indígena Kankuama, Los mayores: autoridades del pueblo Kankuamo. Bogotá. 2010.

Osorio, D. R., "Consensos, conflictos y ambigüedades en torno al territorio: exploración etnohistórica de la lengüeta, Sierra Nevada de Santa Marta”. Maguaré, 32, 1, 20188, 171-204.

Peralta Casas, L., "Categorías espaciales con relación al medio ambiente en la Sierra Nevada de Santa Marta".

¿Qué es la Sierra?, consultado en: http://www.colparques.net/SIERRA 27 de abril del 2020.

Rodríguez, G. A., y Mora Rodriguez, A. Conflictos y judicialización de la política en la Sierra Nevada de Santa Marta. Editorial Universidad del Rosario, 2010. 
M. Serje, M. "La invención de la Sierra Nevada". Antípoda. Revista de Antropología y Arqueología, 7, 2008, 197-229.

A. Ulloa Cubillos, A. La construcción del nativo ecológico: complejidades, paradojas y dilemas de la relación entre los movimientos indígenas y el ambientalismo en Colombia. Bogotá, 2004. 